\title{
Study of Aeromycoflora from Dnyanganga Wild Life sanctuary of Buldhana, Maharashtra
}

\author{
Rasika. N.Patil ${ }^{1}$, Sahadeo .P. Rothe $^{2}$ \\ Research Student, Department of Botany, Shri Shivaji College, Akola (M.S), India ${ }^{1}$ \\ Professor and Head, department of Botany, Shri Shivaji College, Akola (M.S), India ${ }^{2}$
}

\begin{abstract}
Aeromycoflora of Dnyanganga Wild Life sanctuary of Buldhana studied with the help of Petriplate method. Total 250 fungal colonies represented 15 fungal species were observed during the present investigation period. Environmental factor play an important role for the distribution of the fungal spores. The fungal species were Cladosporium, Alternaria, Fusarium, Aspergillus, Penicillium, Curvularia, Rhizopus, Trichoderma species were observed. It is found that maximum percentage contribution is observed for Cladosporium, followed by Aspergillusniger, A. flavus, A fumigates. On the contrary, minimum percentage contribution is observed for Aspergillusnidulans. Spores are released into the environment from fungi growing as saprophytes or parasites. Saprophytes are fungi that grow on dead or decaying organic matter in the soil or elsewhere in the environment. Parasites, on the other hand, infect living host plants. Fungal spore concentrations outdoors are usually high in the late summer or fall.
\end{abstract}

Keywords: Dnyanganga, Environmental, Cladosporium, Saprophytes, Fungal, summer, etc.

\section{INTRODUCTION}

In the present era aerobiology is a vast branch of science which draws information from various disciplines life plant pathology, forestry, mycology, Allergology, Materology, Palynology, Palaebotany, veterinary Science and biodeterioration. Environmental factor play an important role for the distribution of the fungal spores .Several forms of microbes are found in the atmosphere, some of which may be pathogenic to host and some are allergic for human beings (Adhakari et.al 2004). The fungal spores are liberated in air from various sources in massive concentration and can remain airborne for a long time. Fungal spores are important source of various plants and animals diseases.Hence, its concentration should be known.

The study of atmospheric constituents, living and nonliving e.g. Airborne fungal spores are essential step for existence of life and over come on life threatening problems(Arora 2003). The bioparticulates implicated to cause allergic symptoms are pollen grains, fungal spores, insect debris, house dust mites, animal dander, chemicals and foods etc. Among all these agents, pollen grains and fungal spores are the most predominant allergens in the air (Sharma 2004).

However, for the effective diagnosis and therapeutic management of these ailments, detailed information on the daily, seasonal and annual variations of various bioparticles is essential similarly aerobiological investigation. A profusion of fungi exists in the environment. Somefungiareableto cause atmospheric constituents, living and non- living e.g. Airborne fungal spores are essential step for existence of life and over come on life threatening problems. The bioparticulates implicated to cause allergic symptoms are pollen grains, fungal spores, insect debris, house dust mites, animal dander, chemicals and foods etc. Among all these agents, pollen grains and fungal spores are the most predominant allergen.in the air (Lugauskaset.al 2003). However, for the effective diagnosis and therapeutic management of these ailments, detailed information on the daily, seasonal and annual variations of various bioparticles is essential similarly aerobiological investigation.

A profusion of fungi exists in the environment. Some fungi are able to causean invasive infection in otherwise healthy individuals. Other fungi are opportunistic fungi that become invasive when immune defenses are compromised. Diagnosis of fungal infection is difficult. There are many problems when you try to connect a test result disease. Fungi are so abundant and there are so manyvarieties in every environment that it is seldom easy to pick just one cause among many (Kunjam, S. 2007). Environmental factor play an important role for the distribution of the fungal spores.

\section{MATERIALS AND METHODS}

For the study of aeromycoflora, fifteen sterilized Petri plates containing PDA media are exposed 5 to $15 \mathrm{~min}$. in selected site. These exposed Petri plates brought in to the laboratory and incubated at $28 \pm 10^{\circ} \mathrm{C}$ for incubation period. At the end of incubation period fungal colonies are counted, isolated and identified with the help of available literature and finally identified by available mycological keys. 


\section{International Advanced Research Journal in Science, Engineering and Technology}

ISO 3297:2007 Certified

Vol. 4, Issue 2, February 2017

\section{List of Isolated Aeromycoflora}

\begin{tabular}{|l|l|l|}
\hline $\begin{array}{l}\text { Sr. } \\
\text { no }\end{array}$ & Name of Fungi & $\begin{array}{l}\text { Fungal colony } \\
\text { count }(\%)\end{array}$ \\
\hline 1. & Alternariaalternata & 2.76 \\
\hline 2. & Aspergillusflavus & 21.87 \\
\hline 3. & Aspergillusfumigatus & 6.89 \\
\hline 4. & Aspergillusnidulans & 5.70 \\
\hline 5. & Aspergillusniger & 27.58 \\
\hline 6. & Cladosporiumcladosporioides & 0.74 \\
\hline 7. & Curvulariaclavata & 0.50 \\
\hline 8. & Curvularialunata & 0.48 \\
\hline 9. & Fusariummonoliforme & 0.87 \\
\hline 10. & Fusariumoxysporum & 0.85 \\
\hline 11. & Nigrosporaoryzae & 0.54 \\
\hline 12. & Penicilliumnotatum & 2.88 \\
\hline 13. & Phomastipata & 0.35 \\
\hline 14. & Rhizopusstolonifer & 1.76 \\
\hline 15. & Trichodermaviridae & 0.65 \\
\hline 16. & Phomastipada & 0.24 \\
\hline 17. & Mucorsp. & 1.25 \\
\hline
\end{tabular}

Collection sites of Aeromycoflora of Dnyanganga Wild Life sanctuary(Fig 1-4)

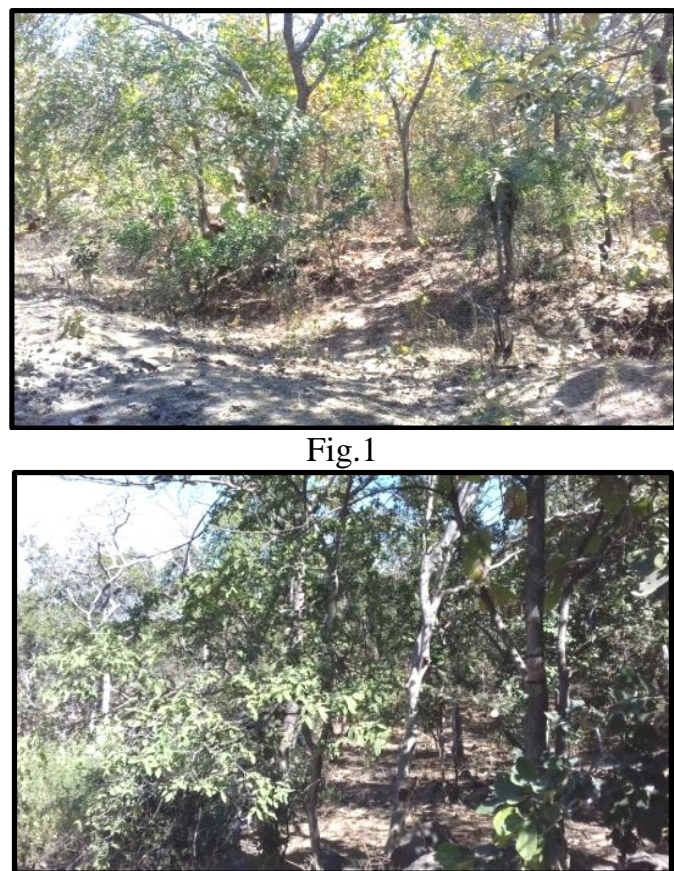

Fig.2

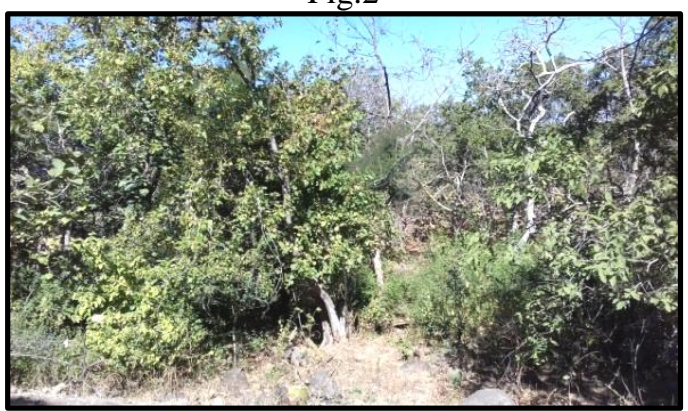

Fig.3

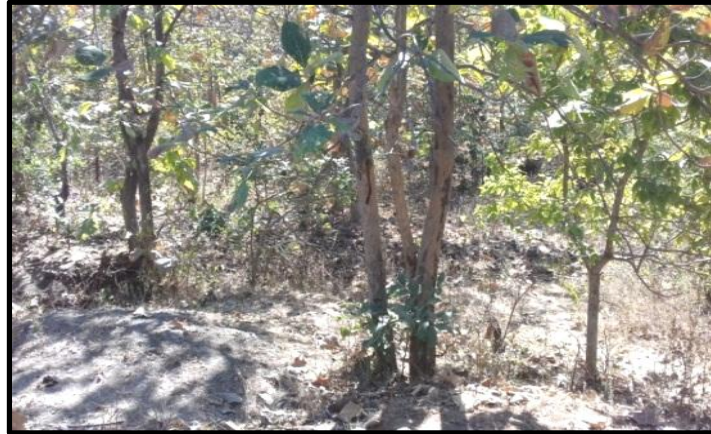

Fig.4

\section{RESULT AND DISCUSSION}

Mixed culture of Aeromycoflora from selected site (Fig 5-6)
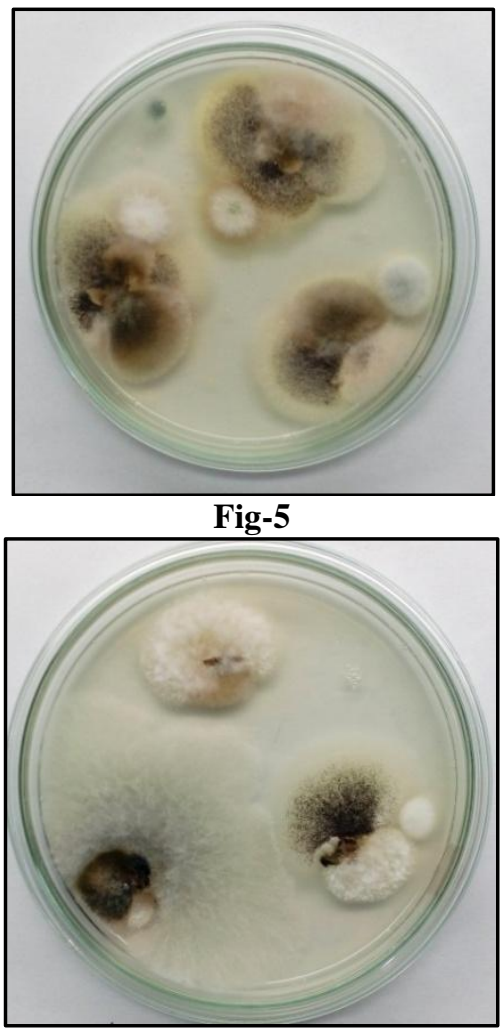

Fig-6

Pure culture so some dominant fungal species (Fig a-e)

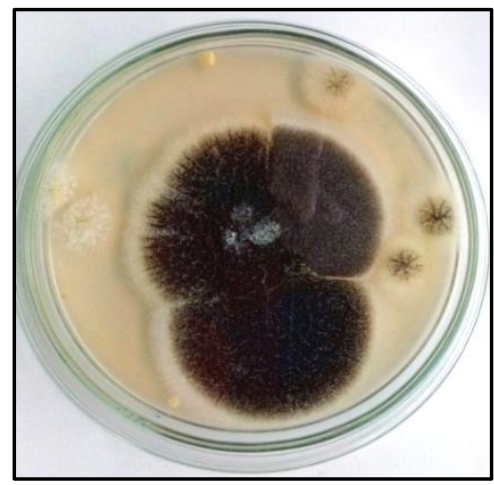

a.Pure culture of Aspergillus niger 
Vol. 4, Issue 2, February 2017

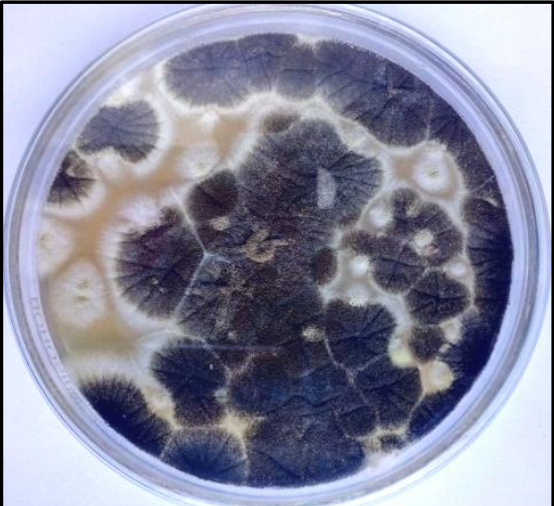

b.Pure culture of Aspergillus nidulans

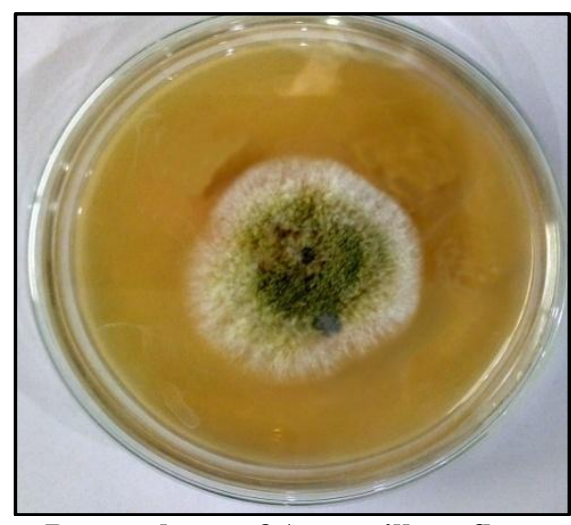

c.Pure culture of Aspergillus flavus

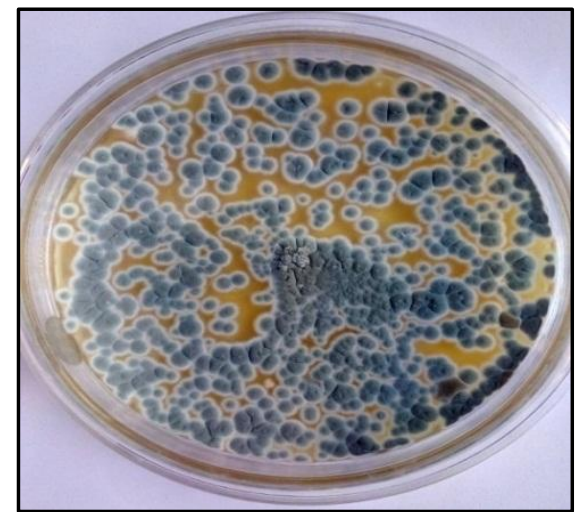

d.Pure culture of Aspergillus fumigatus

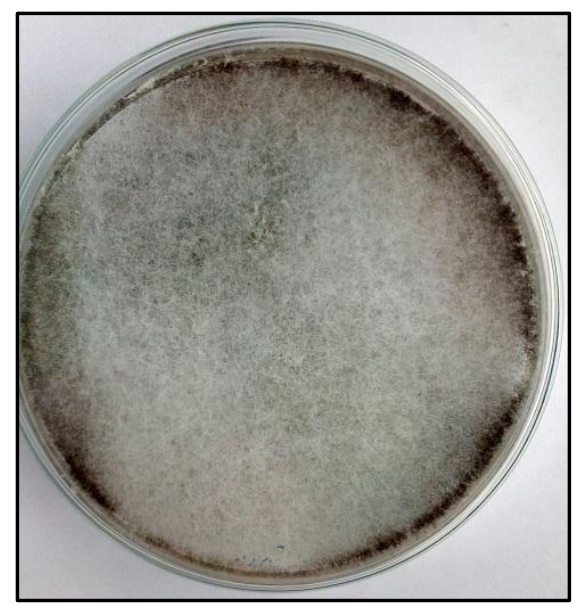

e. Pure culture of Rhizopus stolonifer

\section{RESULT AND DISCUSSION}

Disease increases are particularly common for fungi dispersed in air. These airborne fungi have in the past, been unimportant bexause the human body has an effective immune response has been removed by agents of disease or medical intervention (Sharma K. 2001). With the increased medicalisation of human life, it is likely that disease caused by air borne fungi will increase. Inhalation of spores in most caes has no effect on humans. The spore lodge on the moist surfaces of the lining of the airways and they are subsquently expelled in mucus (Pande2011). The remaining spores are neutralised by the immune response and cause respiratory disease.many molecules including melanin reduce the penetration of radiation especially in the UV range. Melanin is contained in walls of spores and so is the first barrier to UV. However, a rangeof other UV absorbing molecules are found in spores. The consequence is that energy is transformed usually to heat, which can be redily radiated from the spore in air(Sharma 2009).

\section{CONCLUSION}

Present study clear that high contamination of fungal spores with multiple allergic in atmospheric condition poses a serious problem to tribal people of nearby villages of the sanctuary.Thus, this data helped us to prepare the fungal calender on this region and gives scope for the further such studies.

\section{REFERENCES}

[1] Adhikari A, Sen MM, Gupta Bhattacharya S, Chanda S. Volumetric assessment of airborne fungi in two sections of rural indoor dairy cattle. Environment International. 2004; 29:1071-1078. PMID: 14680890.

[2]. Arora, A. and Jain, V. K. 2003 Fungal airspora of Bikaner. Indian J. Aerobiol. 16 (1\&2): P 1-9

[3] Barnett HL, Hunter BB. Illustrated genera of imperfect fungi, 3rd Ed. Published by Burgess Publishing; 1972. ISBN- 10:0808702661, ISBN-13:9780808702665.

[4] Cordeiro RA, Brilhante RSN, Pantoja LDM, Moreirafilho RE, Vieira PRN, Rocha MFG. Isolation of pathogenic yeasts in the air from hospital environments in the city of Fortaleza, northeast Brazil. Brazilian Journal of Infectious Diseases. 2010;14(1):30-34. ISSN 1413-8670. DOI: 10.1590/S1413-86702010000100007.

[5] Arora, A. and Jain, V. K. 2003 Fungal airspora of Bikaner. Indian J. Aerobiol. 16 (1\&2): P 1-9

[6] Barnett HL, Hunter BB. Illustrated genera of imperfect fungi, 3rd Ed. Published by Burgess Publishing; 1972. ISBN- 10:0808702661, ISBN-13:9780808702665.

[7] Cordeiro RA, Brilhante RSN, Pantoja LDM, Moreirafilho RE, Vieira PRN, Rocha MFG. Isolation of pathogenic yeasts in the air from hospital environments in the city of Fortaleza, northeast Brazil. Brazilian Journal of Infectious Diseases. 2010;14(1):30-34. ISSN 1413-8670. DOI: 10.1590/S1413-86702010000100007.

[8] Sharma K. 2001 Studies of aeromycoflora in relation to leaf surface mycoflora of Ocimum sanctum. Ph.D. Thsis, Pt. R. S. U. Raipur (C. G.).

[9] Tiwari, K. L., Jadhav, S. K. and Kunjam, S. R. 2000. Aeromycoflora of Slum area of Raipur (C.G.).Ad. Plant Sci. 19(II) P: 387-390

[10] Kulshrestha, A. and Chauhan, S. V. S. 2001 Aeromycoflora of some hospitals of Agra city. Indian J. Aerobiology. 14 (1\&2): P 3335 
Vol. 4, Issue 2, February 2017

[11] Kunjam, S. 2007 Studies of aeromycoflora of Tribal atmosphere at Panabaras region, Ragnandgaon District (C. G.). Ph.D. Thsis, Pt. R. S. U. Raipur (C. G.).

[12] Lugauskas, Albinas, Sveistyte, Laima, Ulevicius, Vidmantas 2003 Concentration and species diversity of airborne fungi near busy streets in Lithuanian urban area. Ann. Agric. Environ. Med. 10: P 233-239

[13] MajumdarManas ,Ranjan. 2007. An assessment of the indoor mycoflora of school buildings in kolkata. 14th Nat Conf. p33.

[14] Pande BN. Aerobiology and human care. Abstracts from the 45th National Conference of Indian College of Allergy, Asthma and Applied Immunology, held at Aurangabad from 16-18, December, 2011. Indian Journal of Aerobiology. 2011; 24(2): 96-103. ISSNO.0971-1546.

[15] Pandey, A., Palni, L. M. S. and Bisht, D.2001. Microbiological Research. 156(4), pp 377.

[16] Roymon,M.G., Nafde, Seema K., Mukherjee, Arpita., Talukdar, Ayantika. 2007. Identification of some commonly occurring fungi isolated from indoor air samples of common public places. 14th Nat Conf. p34.

[17] Sautour M, Sixt N, Dalle F, L'ollivier C, Fourquenet V, Calinon C. Profiles and seasonal distribution of airborne fungi in indoor and outdoor environments at a French hospital. Science of the Total Environment. 2009; 407:3766-3771. DOI: 10.1016/j.scitotenv. 2009.02.024.

[18] Sharma K. 2009 Incidence of fungal allergens in the air at Raipur. Lab to land 1(3) 98-101

[19] Spengler JD, Samet JM, McCarthy JF. Indoor air quality handbook.In H. A. Burge. Ed. The fungi. NY: McGraw-Hill Companies. 2000; 16:45. ISBN-13: 063- 9785313151, ISBN-10: 0074455494 . 